\title{
Ultraviolet Photolysis of the ClO Dimer
}

\author{
J. Plenge, ${ }^{\dagger}$ R. Flesch, ${ }^{\ddagger}$ and S. Kuihl ${ }^{\S}$ \\ Fachbereich Physik, Universität Osnabrück, Barbarastrasse 7, 49069 Osnabrück, Germany
}

\section{B. Vogel, R. Muiller, and F. Stroh}

Forschungszentrum Jülich, Institut für Stratosphärische Chemie (ICG I), 52425 Jülich, Germany

\section{E. Riihl*}

Institut für Physikalische Chemie, Universität Würzburg, Am Hubland, 97074 Würzburg, Germany

Received: January 21, 2004; In Final Form: April 1, 2004

Photodissociation of the $\mathrm{ClO}$ dimer $(\mathrm{ClOOCl})$ is studied in the ultraviolet regime $(250$ and $308 \mathrm{~nm})$ under collision-free conditions. The primary photolysis products are probed by photoionization mass spectrometry. At both photolysis wavelengths, exclusively the formation of $2 \mathrm{Cl}+\mathrm{O}_{2}$ is observed, corresponding to a primary quantum yield $\gamma_{\mathrm{Cl}}$ near unity. Considering the error limit of the experimental results one obtains $\gamma_{\mathrm{Cl}} \geq 0.98$ at $250 \mathrm{~nm}$ and $\gamma_{\mathrm{Cl}} \geq 0.90$ at $308 \mathrm{~nm}$, respectively. At both photolysis wavelengths the pathway yielding $\mathrm{ClO}$ is not observed, corresponding to $\gamma_{\mathrm{ClO}} \leq 0.02$ at $250 \mathrm{~nm}$ and $\gamma_{\mathrm{ClO}} \leq 0.10$ at $308 \mathrm{~nm}$. Sensitivity studies of these results with respect to ozone depletion in the stratosphere regarding photochemically induced ozone loss are discussed using model simulations. These simulations suggest that a change of $\gamma_{\mathrm{Cl}}$ from 1.0 to 0.9 leads to a reduction of polar ozone loss of $\sim 5 \%$.

\section{Introduction}

Numerous theoretical and experimental studies have been devoted to the stability, spectroscopy, and photochemistry of the $\mathrm{ClO}$ dimer $\left(\mathrm{Cl}_{2} \mathrm{O}_{2}\right)$. These are mainly motivated by the observation of strong stratospheric ozone loss in polar spring. ${ }^{1}$ A catalytic reaction cycle involving $\mathrm{Cl}_{2} \mathrm{O}_{2}$ is believed to play an important role: ${ }^{2}$

$$
\begin{gathered}
2 \mathrm{ClO}+\mathrm{M} \rightleftharpoons \mathrm{Cl}_{2} \mathrm{O}_{2}+\mathrm{M} \\
\mathrm{Cl}_{2} \mathrm{O}_{2}+h v \rightarrow \mathrm{ClOO}+\mathrm{Cl} \\
\mathrm{ClOO}+\mathrm{M} \rightarrow \mathrm{Cl}+\mathrm{O}_{2}+\mathrm{M} \\
2\left(\mathrm{Cl}+\mathrm{O}_{3} \rightarrow \mathrm{ClO}+\mathrm{O}_{2}\right)
\end{gathered}
$$

$$
2 \mathrm{O}_{3}+h v \rightarrow 3 \mathrm{O}_{2}
$$

In addition to the photolysis channel (2), $\mathrm{Cl}_{2} \mathrm{O}_{2}$ may undergo a competitive photolysis pathway leading to $\mathrm{ClO}$ formation:

$$
\mathrm{Cl}_{2} \mathrm{O}_{2}+h v \rightarrow 2 \mathrm{ClO}
$$

This reaction leads to a null cycle in the balance of atmospheric ozone. Its atmospheric relevance was discussed by Eberstein and Minton et al. 3,4

* Corresponding author. Phone: $++49-931-888$ 6300. Fax: $++49-$ 931-888 6302. E-mail: eruehl@phys-chemie.uni-wuerzburg.de.

Present address: Department of Chemistry, University of California at Berkeley

$\doteqdot$ Present address: Institut für Physikalische Chemie, Universität Würzburg, Germpany

$\S$ Present address: Institut für Umweltphysik, Universität Heidelberg, Germany
Several theoretical studies have been carried out to investigate the structure, stability, and photochemistry of the $\mathrm{ClO}$ dimer. ${ }^{5-10}$ According to these works, $\mathrm{Cl}_{2} \mathrm{O}_{2}$ occurs most likely in the stratosphere as dichlorine peroxide $(\mathrm{ClOOCl})$, whereas other isomers, such as $\mathrm{ClOClO}$ or $\mathrm{ClClO}_{2}$, are believed to be less stable. The photolysis of $\mathrm{ClOOCl}$ yielding $2 \mathrm{Cl}+\mathrm{O}_{2}$ is the dominant process, whereas only small amounts of $\mathrm{ClO}$ are formed at short ultraviolet (UV)-photolysis wavelengths. ${ }^{9}$ The quantum yield for $2 \mathrm{ClO}$ formation is calculated to be zero below $4.4 \mathrm{eV}$ photon energy. It reaches 0.05 in the $4.4-5.0 \mathrm{eV}$ regime (248 $\mathrm{nm} \leq \lambda \leq 282 \mathrm{~nm}$ ). Kaledin and Morokuma studied the photodissociation dynamics of $\mathrm{ClOOCl}$ considering the synchronous and sequential formation of $2 \mathrm{Cl}+\mathrm{O}_{2}$ at $308 \mathrm{~nm}$, and there are three fragmentation routes at $248 \mathrm{~nm}$ yielding $2 \mathrm{Cl}+$ $\mathrm{O}_{2}, \mathrm{Cl}+\mathrm{O}+\mathrm{ClO}$, and $2 \mathrm{Cl}+2 \mathrm{O}$, respectively. ${ }^{10}$

First experiments on the photolysis of $\mathrm{ClOOCl}$ indicated that primarily atomic chlorine is formed at $254 \mathrm{~nm} .{ }^{11}$ This result was confirmed for $308 \mathrm{~nm}$, where a quantum yield close to unity $\left(\gamma_{\mathrm{Cl}}=1.03 \pm 0.12\right)$ was reported for $\mathrm{Cl}$ formation. ${ }^{12}$ More recently, Moore et al. found experimental evidence for the photolysis channel according to eq $6 .{ }^{13}$ They deduced from molecular beam experiments a 9:1 preference for the formation of $2 \mathrm{Cl}+\mathrm{O}_{2}$ (cf. channel (2)), where photolysis experiments were carried out at 248 and $308 \mathrm{~nm}$, respectively. Specifically, they reported for the photolysis at $248 \mathrm{~nm}: \gamma_{\mathrm{Cl}}=0.88 \pm 0.07$ and $\gamma_{\mathrm{ClO}}=0.12 \pm 0.07$. For the photolysis at $308 \mathrm{~nm}$ the following values are reported: $\gamma_{\mathrm{Cl}}=0.9 \pm 0.1$ and $\gamma_{\mathrm{ClO}}=0.1$ $\pm 0.1,{ }^{13}$ where the quantum yields of both channels (2) and (6) add to unity.

The present study aims to use a novel pump-probe laboratory approach for the reliable detection of the primary photofragments of the $\mathrm{ClO}$ dimer including their branching ratio at various ultraviolet wavelengths. Model simulations are performed to 
emphasize the atmospheric implications of the results from laboratory work.

\section{Experimental Section}

The experimental setup consists of the following components: (i) a flow tube for the efficient $\mathrm{ClO}$ and $\mathrm{ClO}$ dimer production (cf. ref 14); (ii) an excimer-pumped dye laser (Lambda Physik: LPX 202 and Scanmate) equipped with a frequency doubling unit $(\mathrm{BBO}(\mathrm{I})$-crystal); and (iii) a timecorrelated, tunable vacuum-ultraviolet (VUV) radiation source (laser-produced plasma), which is typically delayed by $100 \mathrm{~ns}$ with respect to the primary photolysis pulse. It delivers radiation pulses of $25 \mathrm{~ns}$ length (typically $10^{9}$ photons/s) in the energy regime $8 \mathrm{eV} \leq E \leq 25 \mathrm{eV}(155 \mathrm{~nm} \geq \lambda \geq 50 \mathrm{~nm}$, photon bandwidth $\Delta \lambda=0.8 \mathrm{~nm}$ ) and (iv) a time-of-flight mass spectrometer (TOF) for cation separation and detection. Further details have been published elsewhere. ${ }^{15}$

$\mathrm{ClO}$ is generated in the flow tube by the following reaction: $\mathrm{Cl}+\mathrm{OClO} \rightarrow 2 \mathrm{ClO}$. We used a gas mixture of $5 \% \mathrm{Cl}_{2}$ in $\mathrm{He}$ for $\mathrm{Cl}$ production in a microwave discharge at typically $p=5$ $\mathrm{hPa}$. The $\mathrm{OClO}$ source has been described before. ${ }^{16}$ The formation of $\mathrm{Cl}_{2} \mathrm{O}_{3}$ is avoided by keeping the OClO partial pressure as low as possible, so that $\mathrm{Cl}_{2} \mathrm{O}_{3}{ }^{+}(\mathrm{m} / \mathrm{z} 118,120,122)$ is not observed in photoionization mass spectra. This implies using an excess of atomic chlorine relative to $\mathrm{OClO}$. The $\mathrm{ClO}$ dimer is efficiently produced by cooling the flow tube to 170 $\mathrm{K}$. It is known that the rate constant of the above-mentioned reaction $\mathrm{Cl}+\mathrm{OClO}$ is only slightly temperature dependent, which increases most likely with decreasing temperature. ${ }^{17} \mathrm{We}$ assume that the $\mathrm{ClO}$ dimer in the sample is mostly $\mathrm{ClOOCl}$. This assignment is in agreement with earlier work. ${ }^{18}$ There are also contributions from $\mathrm{ClClO}_{2}$. Evidence for this species is found from the mass signals of $\mathrm{ClO}_{2}{ }^{+}(\mathrm{m} / \mathrm{z}$ 67, 69). Photoion yields of $\mathrm{ClO}_{2}{ }^{+}$have been recorded by selecting these mass signals, while scanning the VUV energy. As a result, the appearance energy (AE) of these cations is found at $11.34 \pm$ $0.05 \mathrm{eV}$, which is well above the ionization energy (IE) of $\mathrm{OClO}$ $(\mathrm{IE}=10.35 \mathrm{eV}) .{ }^{16}$ The $\mathrm{AE}$ is in excellent agreement with the ionic fragmentation process $\mathrm{ClClO}_{2}+\rightarrow \mathrm{ClO}_{2}{ }^{+}+\mathrm{Cl}+\mathrm{e}^{-}$, using data from ref 19. We estimate from the photolysis experiments, which are described in the following, that the $\mathrm{Cl}_{2} \mathrm{O}_{2}$ sample contains $83 \pm 2 \% \mathrm{ClOOCl}$ and $17 \pm 2 \% \mathrm{ClClO}_{2}$. Evidence for the formation of higher chlorine oxides is not found.

The gaseous sample emerges from the flow tube into a high vacuum recipient, where the ionization region of the TOF is located. There, the photolysis and the photoionization light pulses are spatially overlapped. The pressure in the ionization region is $\sim 10^{-3} \mathrm{~Pa}$, so that the photolysis occurs under collisionfree conditions and primary photofragments are detected. The photon flux of the photolysis pulse is kept low $\left(<30 \mathrm{~mJ} / \mathrm{cm}^{2}\right)$ to avoid multiphoton excitation and ionization.

The photolysis experiments are carried out at 250 and 308 $\mathrm{nm}$, respectively. These wavelengths were chosen in order to compare the present results to earlier experimental works. ${ }^{11-13}$ A typical set of photoionization mass spectra at a given UVphotolysis wavelength and VUV-photon energy consist of (i) photoionization by VUV-radiation without primary photolysis, (ii) UV-photoexcitation without subsequent VUV-photoionization, so that possible contributions from multiphoton ionization are identified, and (iii) primary UV-photolysis followed by subsequent VUV-photoionization. Data reduction is carried out by subtracting the mass spectra (i) and (ii) from the pumpprobe TOF mass spectrum (iii). The resulting difference mass spectra are termed photolysis mass spectra in the following,

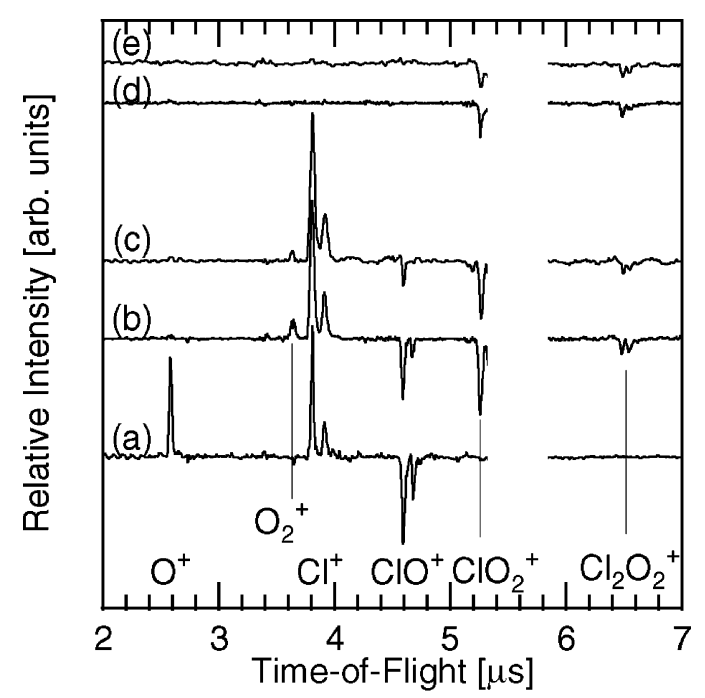

Figure 1. Photolysis mass spectra of $\mathrm{ClO}$ and the $\mathrm{ClO}$ dimer. The photolysis wavelengths $\lambda$ are given in nm, the VUV photon energies $E$ that are used for photoionization are given in eV. Experimental conditions: (a) $T=298 \mathrm{~K}, \lambda=250 \mathrm{~nm}, E=13.45 \mathrm{eV}$; (b) $T=170$ $\mathrm{K}, \lambda=250 \mathrm{~nm}, E=13.45 \mathrm{eV}$; (c) $T=170 \mathrm{~K}, \lambda=308 \mathrm{~nm}, E=13.45$ $\mathrm{eV}$; (d) $T=170, \lambda=250 \mathrm{~nm}, E=11.43 \mathrm{eV}$; (e) $T=170 \mathrm{~K}, \lambda=308$ $\mathrm{nm}, E=11.43 \mathrm{eV}$.

since all mass signals are exclusively due to the primary UVphotolysis processes. Positive mass signals correspond to species that are formed by photolysis, and negative cation intensity is observed for those species that are consumed by photolysis, if contributions from ionic fragmentation are absent.

About $20 \%$ of the parent species, $\mathrm{ClO}$ and $\mathrm{Cl}_{2} \mathrm{O}_{2}$, are typically photolyzed at $250 \mathrm{~nm}$, as inferred from the change of the parent cation mass signals. The photolysis yield is smaller at longer photolysis wavelengths, i.e., at $308 \mathrm{~nm}$, as a result of the decreased photoabsorption cross section of both species (cf. refs 19 and 20).

\section{Results and Discussion}

Ultraviolet Photolysis of the CIO Dimer. Photolysis experiments of the $\mathrm{ClO}$ dimer are carried out at 250 and $308 \mathrm{~nm}$. Figure 1 shows a series of photolysis mass spectra: Figure 1a shows the photolysis of $\mathrm{ClO}(T=298 \mathrm{~K})$ at $250 \mathrm{~nm}$, yielding $\mathrm{Cl}\left({ }^{2} \mathrm{P}_{3 / 2}\right)+\mathrm{O}\left({ }^{1} \mathrm{D}\right) .{ }^{21,22}$ Intense positive mass signals are due to photoionization of these atomic photolysis products. The VUV photon energy is set to $13.45 \mathrm{eV}$ because $\mathrm{O}\left({ }^{1} \mathrm{D}\right)$ is probed selectively at this photon energy by autoionization. ${ }^{23}$ The negative intensity of $\mathrm{ClO}^{+}$indicates that $\mathrm{ClO}$ is consumed by UV-photolysis. The following changes are observed after cooling the flow system to $170 \mathrm{~K}$, where no free $\mathrm{ClO}$ is detected (see Figure 1b): (i) the intense $\mathrm{O}^{+}$signal has vanished; (ii) an additional mass signal, corresponding to $\mathrm{O}_{2}{ }^{+}$, occurs; (iii) mass signals with negative intensity are detected for $\mathrm{ClO}_{2}{ }^{+}$and $\mathrm{Cl}_{2} \mathrm{O}_{2}{ }^{+}$; and (iv) a substantial $\mathrm{Cl}^{+}$signal is found.

The lack of an $\mathrm{O}^{+}$signal indicates that there is little free $\mathrm{ClO}$ in the sample. The occurrence of $\mathrm{Cl}^{+}$together with $\mathrm{O}_{2}{ }^{+}$ gives evidence for reaction 2 . It is possible that an intermediate $\mathrm{ClOO}$ is formed by $\mathrm{UV}$-photolysis of $\mathrm{ClOOCl}$, which is subsequently photoionized, yielding $\mathrm{Cl}+\mathrm{O}_{2}{ }^{+}$. However, it is known that the $\mathrm{ClOO}$ is photolytically formed in an excited state that readily decomposes into $\mathrm{Cl}+\mathrm{O}_{2}$ in the femtosecond time regime. ${ }^{9}$ As a result, any $\mathrm{ClOO}$ that is formed as an intermediate via photolysis will be probed as channel (2). This also implies that the present setup is not well-suited to distinguish between the simultaneous and sequential decay dynamics of $\mathrm{ClOOCl}$. 
$\mathrm{Cl}_{2} \mathrm{O}_{2}$ is consumed by $\mathrm{UV}$-photolysis, yielding a negative $\mathrm{Cl}_{2} \mathrm{O}_{2}{ }^{+}$signal in the photolysis mass spectrum (cf. Figure $1 \mathrm{~b}$ ). The negative $\mathrm{ClO}_{2}{ }^{+}$signal shows that $\mathrm{ClClO}_{2}$ is present in the cold flow system (cf. ref 14). The intense $\mathrm{Cl}^{+}$signal under cold conditions, where nearly all $\mathrm{ClO}$ radicals are bound in $\mathrm{ClOOCl}$, indicates that the $\mathrm{ClOOCl}$ is efficiently photolyzed into $2 \mathrm{Cl}+$ $\mathrm{O}_{2}$ (cf. eq 2). The relevance of the competing photolysis channel (6) cannot be reliably deduced from Figure $1 \mathrm{~b}$, since the $\mathrm{ClO}^{+}$ intensity is negative. This finding is rationalized as follows: (i) $\mathrm{ClOOCl}$ is photolyzed, so that there is less of this species in the gas phase yielding a weaker $\mathrm{ClO}^{+}$signal from fragmentation of $\mathrm{ClOOCl}^{+}$and (ii) if $\mathrm{ClOOCl}$ photolyzes into $2 \mathrm{ClO}$ via eq 6 , then the nascent $\mathrm{ClO}$ must contribute to a positive $\mathrm{ClO}^{+}$signal. The experimental $\mathrm{ClO}^{+}$intensity is expected to be the sum of both contributions. However, it is not possible to evaluate from Figure $1 \mathrm{~b}$ the amount of nascent $\mathrm{ClO}$ that is photoionized. Therefore, Figure 1b is only sensitive to photolysis channel (2). This is similar to Figure 1c, where the photolysis wavelength is set to $308 \mathrm{~nm}$, indicating that there are minor visible changes in photolysis behavior as a function of UV wavelength. However, a specific indicator for the occurrence of different $\mathrm{Cl}_{2} \mathrm{O}_{2}$ isomers, such as $\mathrm{ClOOCl}$ and $\mathrm{ClClO}_{2}$, is the ratio of the mass lines of $\mathrm{Cl}^{+}(\mathrm{m} / \mathrm{z}, 35,37)$ and $\mathrm{O}_{2}{ }^{+}(\mathrm{m} / \mathrm{z}, 32): \mathrm{I}_{\mathrm{Cl}^{+}} / \mathrm{I}_{\mathrm{O}_{2}}{ }^{+}$. These cations are formed via photolysis of $\mathrm{ClOOCl}$, yielding after photoionization of the corresponding neutrals $2 \mathrm{Cl}^{+}+\mathrm{O}_{2}{ }^{+}$, whereas the photolysis of $\mathrm{ClClO}_{2}$ contributes to the $\mathrm{Cl}^{+}$and $\mathrm{OClO}^{+}$signals. Note that changes to the $\mathrm{OClO}^{+}$signal by photoionization of nascent $\mathrm{OClO}$ that is formed from photolyzed $\mathrm{ClClO}_{2}$ cannot be analyzed. This is due to the formation of $\mathrm{OClO}^{+}$via fragmentation of $\mathrm{ClClO}_{2}^{+}$without primary photolysis. As a result of both contributions a negative $\mathrm{OClO}^{+}$-mass signal is found in the photolysis mass spectra (see Figure 1, parts $\mathrm{b}$ and $\mathrm{c}$ ). We observe at $250 \mathrm{~nm}$ and subsequent photoionization at $13.45 \mathrm{eV}$ that $I_{\mathrm{Cl}^{+}} / I_{\mathrm{O}_{2}}{ }^{+}=9.6 \pm 1.4$. At 308 nm we obtain from Figure $1 \mathrm{c} I_{\mathrm{Cl}^{+}}+I_{\mathrm{O}_{2}}{ }^{+}=36 \pm 4$. Note that a pure sample of $\mathrm{ClOOCl}$ would give at both photolysis wavelengths the same ratio $I_{\mathrm{Cl}^{+}} / I_{\mathrm{O}_{2}}{ }^{+}=8$, using the stoichiometry of channel (2) along with the known photoionization cross sections $\sigma\left(\mathrm{O}_{2}\right)=6 \mathrm{Mb},{ }^{24} \sigma(\mathrm{Cl})=24 \mathrm{Mb}^{25}$ at $13.45 \mathrm{eV}$. This cation ratio implies that both photolysis products are formed in their ground state. The experimental results indicate that there are evidently different species present that change $I_{\mathrm{Cl}^{+}} / I_{\mathrm{O}_{2}}{ }^{+}$. Using the photoionization cross section of the neutral photolysis products at $13.45 \mathrm{eV}$, considering the bandwidth of the LPP radiation source, as well as the absorption cross sections at both photolysis wavelengths, ${ }^{20,26}$ we obtain that $83 \pm 2 \%$ of the $\mathrm{Cl}_{2} \mathrm{O}_{2}$ species in the sample are due to $\mathrm{ClOOCl}$, whereas $17 \pm 2 \%$ correspond to $\mathrm{ClClO}_{2}$, as already mentioned above. The presence of $\mathrm{ClClO}_{2}$ contributes about $12 \%$ to the $\mathrm{Cl}^{+}$mass signal via UV-photolysis at $250 \mathrm{~nm}$ and subsequent photoionization at $13.45 \mathrm{eV}$. Note that this situation changes at $308 \mathrm{~nm}$, where the contribution of $\mathrm{ClClO}_{2}$ to the $\mathrm{Cl}^{+}$signal is dominant, so that only $\sim 30 \%$ of this mass signal comes from the photolysis of $\mathrm{ClOOCl}$.

The relevance of channel (6) is determined by reducing the VUV photon energy to $11.43 \mathrm{eV}$ (cf. Figure 1, parts d and e). This photon energy is below the threshold of ionic fragmentation of $\mathrm{ClOOCl}$. The appearance energy of $\mathrm{ClO}^{+}$from $\mathrm{ClOOCl}$ is calculated to be $11.60 \pm 0.08 \mathrm{eV}$. The photoionization cross section of $\mathrm{ClO}$ is known to be $15 \pm 2 \mathrm{Mb}$ at $11.5 \mathrm{eV},{ }^{25}$ so that any $\mathrm{ClO}$ is sensitively detected by photoionization mass spectrometry, if it is formed via eq 6 . The sensitivity of $\mathrm{ClO}$ detection is expected to be further increased by about $10 \%$, if $\mathrm{ClO}$ is formed vibrationally excited upon photolysis. This is a result of an increased photoionization cross section of vibrationally excited $\mathrm{ClO}$ (cf. ref 27). Figure 1d clearly shows that there is no evidence for $\mathrm{ClO}^{+}$, if the photolysis wavelength is set to $250 \mathrm{~nm}$. Identical results are obtained from photolysis experiments at $308 \mathrm{~nm}$ (see Figure 1e), but the signal-to-noise ratio is lower as a result of the small absorption cross section of $\mathrm{ClOOCl}$ at $308 \mathrm{~nm}\left(\sigma_{308 \mathrm{~nm}}=0.341 \mathrm{Mb} ; \sigma_{250 \mathrm{~nm}}=5.889\right.$ $\left.\mathrm{Mb}^{20}\right)$. The present results indicate that there is no evidence for photolysis channel (6). This implies that we can only determine an upper limit of the primary quantum yield for $2 \mathrm{ClO}$ formation $\gamma_{\text {ClO }}$. This quantity is mostly limited by the signal-to-noise ratio and the signal strengths of the experimental data, as will be outlined below. We assume that each UV photon absorbed by $\mathrm{ClOOCl}$ leads to photodissociation, according to the possible channels (2) and (6). As a result, the quantum yields of both channels add to unity. This assumption appears to be justified, since there are no other processes known to occur upon UVexcitation of $\mathrm{ClOOCl}$ (cf. ref 13) and electronically excited $\mathrm{ClOOCl}$ is unlikely to undergo a radiative decay via the emission of fluorescence photons. The primary quantum yield for $2 \mathrm{Cl}$ formation $\gamma_{\mathrm{Cl}}$ and $2 \mathrm{ClO}$ formation $\gamma_{\mathrm{ClO}}$ depends on the mass spectrometric intensities $I$ and the photoionization cross sections $\sigma$ as follows:

$$
\gamma_{\mathrm{Cl}}=\left(I_{\mathrm{Cl}^{+}} / \sigma_{\mathrm{Cl}}\right) /\left[\left(I_{\mathrm{Cl}^{+}} / \sigma_{\mathrm{Cl}}\right)+\left(I_{\mathrm{ClO}^{+}} / \sigma_{\mathrm{ClO}}\right)\right]
$$

and

$$
\gamma_{\mathrm{ClO}}=\left(I_{\mathrm{ClO}^{+}} / \sigma_{\mathrm{ClO}}\right) /\left[\left(I_{\mathrm{Cl}^{+}} / \sigma_{\mathrm{Cl}}\right)+\left(I_{\mathrm{ClO}^{+}} / \sigma_{\mathrm{ClO}}\right)\right]
$$

An estimate for the error limits of both quantum yields $\gamma_{\mathrm{Cl}}$ and $\gamma_{\mathrm{ClO}}$ is essential to quantify the quality of the present results in comparison with previous works. ${ }^{12,13}$ This is accomplished by considering the detection limits of both cations. The estimate of the detection limits is based on the cation signals strengths that are measured as voltage pulses by a digital oscilloscope, where the signals are loaded into $50 \Omega$. We observe no $\mathrm{ClO}^{+}$ intensity in the experimental time-of-flight mass spectra (Figure $1 \mathrm{~d}, \mathrm{e})$, where the standard deviation $\sigma$ of the cation background signal corresponds to $0.05 \pm 0.01$ (see Figure 1d) and $0.135 \pm$ $0.045 \mathrm{mV}$ (see Figure 1e), respectively. Furthermore, we use as a detection limit $3 \sigma$, which is $0.15 \mathrm{mV}$ at $250 \mathrm{~nm}$ and 0.405 $\mathrm{mV}$ at $308 \mathrm{~nm}$, respectively. The ratio between the detected cation intensity and the corresponding photoionization cross section is proportional to the number of neutral photolysis products in the ionization region. This corresponds to $0.027 \mathrm{mV}$ per $\mathrm{Mb}$ photoionization cross section of $\mathrm{ClO}$ for the primary photolysis at $308 \mathrm{~nm}$ (cf. Figure 1e). Similarly, one obtains for the detection of atomic chlorine at the same photolysis wavelength via photoionization mass spectrometry $0.228 \mathrm{mV}$ per $\mathrm{Mb}$ photoionization cross section of atomic chlorine (see Figure 1c). As a result of this estimate, we obtain for the photolysis of $\mathrm{ClOOCl}$ at $308 \mathrm{~nm}$ using eq 8 as an upper limit $\gamma_{\mathrm{ClO}} \leq 0.10$. This corresponds to $\gamma_{\mathrm{Cl}} \geq 0.90$, assuming that both quantum yields add to unity. The same estimate yields for the primary photolysis at $250 \mathrm{~nm}: \gamma_{\mathrm{ClO}} \leq 0.02$, so that $\gamma_{\mathrm{Cl}} \geq$ 0.98 . Note that the results are not affected by the photon energy that is used for photoionization, since only $I / \sigma$ ratios appear in eqs 7 and 8, which are independent of the photon energy after appropriate normalization to the photon flux and the monochromator bandwidth. Possible systematic errors from the presence of species, which lead to $\mathrm{Cl}$ formation upon UVphotolysis, are considered as follows: Weak contributions to $I_{\mathrm{Cl}^{+}}$from $\mathrm{Cl}_{2}$, which remain from $\mathrm{Cl}$ production, have been subtracted prior to the data analysis. These are negligible at 

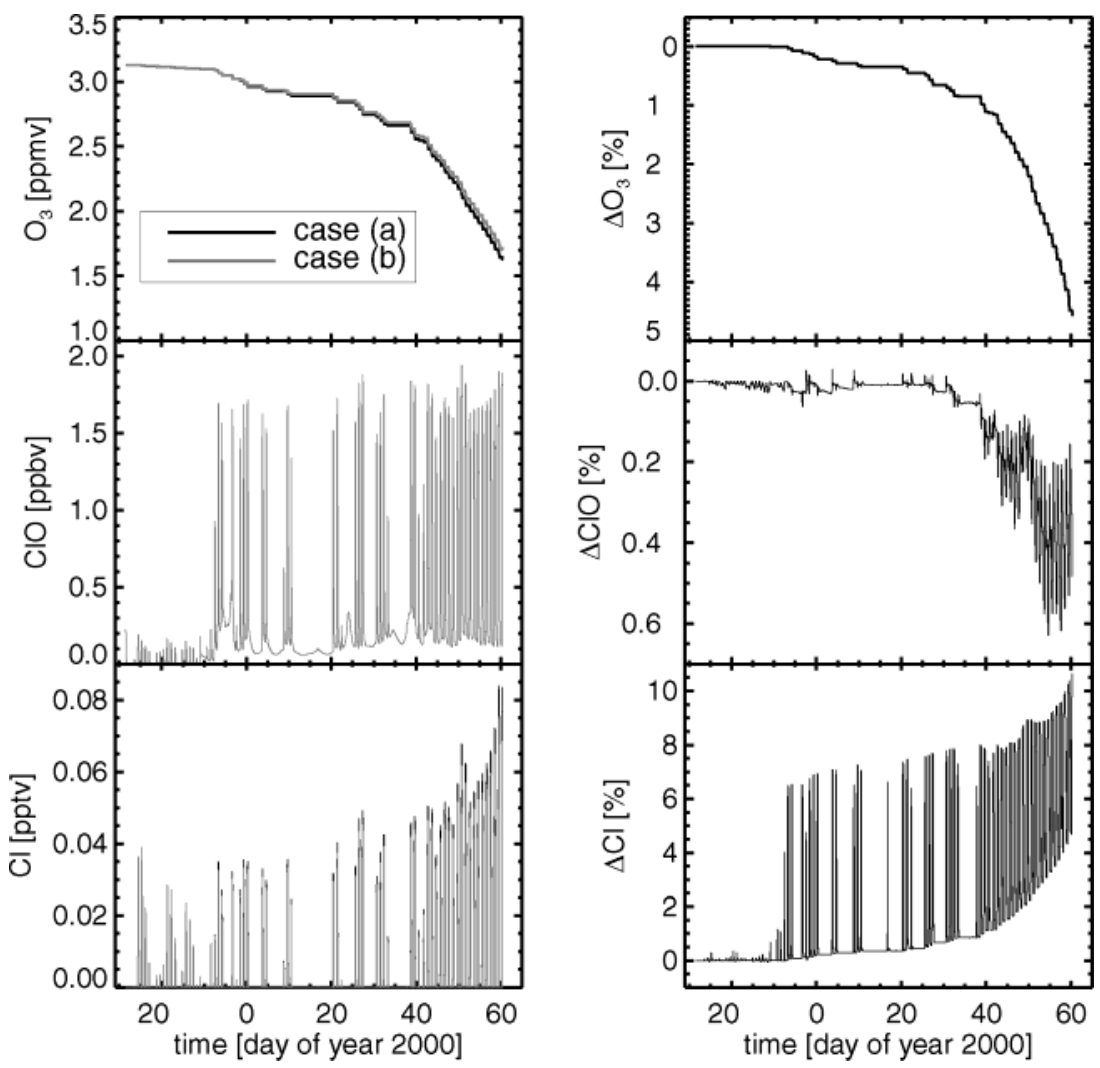

Figure 2. Model simulations for the time period between December 3, 1999 and March 1, 2000 using the CLaMS model at a potential temperature of $475 \mathrm{~K}$. Cases a $\left(\gamma_{\mathrm{Cl}}=1\right)$ and case $\mathrm{b}\left(\gamma_{\mathrm{Cl}}=0.9, \gamma_{\mathrm{ClO}}=0.1\right)$ consider the mixing ratios of ozone (top), $\mathrm{ClO}$ (middle), and $\mathrm{Cl}$ (bottom). The left-hand patterns show the calculations for cases a and $b$. The right-hand patterns show the relative change between both cases.

$250 \mathrm{~nm}$, since the absorption cross section of $\mathrm{Cl}_{2}$ is known to be $\sim 4 \times 10^{-4} \mathrm{Mb}$ at $250 \mathrm{~nm} .{ }^{28}$ As a result, this source of atomic chlorine is much less efficient than $\mathrm{ClOOCl}\left(\sigma_{\mathrm{ClOOCl}}=5.889\right.$ $\mathrm{Mb}$ at $\left.250 \mathrm{~nm}^{20}\right)$. Other sources contributing to $I_{\mathrm{Cl}^{+}}$, such as $\mathrm{OClO}$, are also expected to be quite weak at $250 \mathrm{~nm}\left(\sigma_{\mathrm{OClO}} \approx\right.$ $0.2 \mathrm{Mb}$ ). However, this situation changes at $308 \mathrm{~nm}$, where the absorption cross sections of impurities, such as $\mathrm{ClClO}_{2}$, increase relative to that of $\mathrm{ClOOCl}$, as outlined above. This leads, together with the low absorption cross section of $\mathrm{ClOOCl}$, to a significantly increased error limit of $\gamma_{\mathrm{ClO}}$.

The present results indicate that the error limits of the primary quantum yields of the $\mathrm{ClO}$-dimer photolysis channels are considerably smaller at $250 \mathrm{~nm}$ than in previous work. ${ }^{13}$ At 308 $\mathrm{nm}$ we derive a somewhat larger error limit than at $250 \mathrm{~nm}$, which is similar to previous works. ${ }^{12,13}$ This is essentially due to impurities in the ClO-dimer sample, which are difficult to avoid. They contribute efficiently to photoionization of the photolysis products of $\mathrm{Cl}_{2} \mathrm{O}_{2}$. The present work yields no evidence for $\mathrm{ClO}$ formation via eq 6 . This is unlike previous work, where $\mathrm{ClO}$ is clearly identified as a photolysis product at $308 \mathrm{~nm} .{ }^{13}$ Possible reasons for this discrepancy may be found in the different preparation routes of the $\mathrm{ClOOCl}$ compared to ref 13 .

Sensitivity Study of the ClO-Dimer Photolysis in the Stratosphere. Photodissociation of the $\mathrm{ClO}$ dimer is a key step in one of the dominant catalytic ozone loss cycles, which are responsible for stratospheric ozone depletion in polar spring. ${ }^{29}$ Therefore, the results of the present laboratory experiments have direct implications for the understanding of polar ozone loss. These implications are investigated by model simulations with use of $\gamma_{\mathrm{Cl}}$ and $\gamma_{\mathrm{ClO}}$ from the present experiments. We use a box model version of the Chemical Lagrangian Model of the Stratosphere (CLaMS) $)^{30,31}$ that simulates both the chemistry of multiple air parcels and their transport. This model study is based on simulations ${ }^{32}$ of the temporal evolution of chlorine activation and of ozone loss in the Arctic winter 1999/2000. In situ observations of the $\mathrm{ClO}$ mixing ratios were obtained from a balloon-borne instrument launched in Kiruna, North Sweden, on March 1, 2000, where quasi-simultaneously measured ozone mixing ratios are available, as well. The measured $\mathrm{ClO}$ and ozone mixing ratios are compared to CLaMS simulations, which are initialized for early winter conditions. This allows us to infer the chlorine activation and ozone loss during the winter for altitudes between approximately 13 and $15 \mathrm{~km}$. The model simulations are performed for the time period December 3, 1999 until March 1, 2000 along trajectories taking the diabatic descent into account. At $475 \mathrm{~K}$ potential temperature, corresponding to $\sim 20.5 \mathrm{~km}$ altitude, full chlorine activation and substantial ozone loss are simulated, which is in agreement with the measurements in the stratosphere. Therefore, we repeat this model simulation at $475 \mathrm{~K}$ for case a $(\mathrm{ClOOCl}$ exclusively decays via eq 2, i.e., $\gamma_{\mathrm{Cl}}=1.0$ ) and case $\mathrm{b}$ (using $\gamma_{\mathrm{Cl}}=0.9$ and $\gamma_{\mathrm{ClO}}=0.1$ ). These scenarios are motivated by the error limit given in previous work (cf. ref 13) and the regime of error limits obtained from this work at $308 \mathrm{~nm}$.

Increasing $\gamma_{\mathrm{ClO}}$ should lead to a lower efficiency of the $\mathrm{ClO}$ dimer cycle (cf. ref 29). Indeed, we find up to $~ 5 \%$ lower ozone mixing ratios until March 1, 2000 employing case a compared to case b (cf. Figure 2). Furthermore, for given $\mathrm{O}_{3}$ and $\mathrm{CH}_{4}$ concentrations, the ratio between $\mathrm{Cl}$ and $\mathrm{ClO}$ is determined by the $\mathrm{ClO}$ dimer photolysis, especially since the $\mathrm{NO}$ and $\mathrm{O}$ mixing ratios are low in the late winter lower stratosphere. In case a higher $\mathrm{Cl}$ mixing ratios are produced, which enhance the ozone destruction rate compared to case $\mathrm{b}$. The model simulations also show that the reaction rate of $\mathrm{Cl}+\mathrm{CH}_{4} \rightarrow \mathrm{CH}_{3}+\mathrm{HCl}$ is higher in case a than in case b. Therefore, more $\mathrm{HCl}$ and less $\mathrm{CH}_{4}$ are 
found in case a. Finally, more $\mathrm{OH}$ and $\mathrm{HO}_{2}$ is observed in case a owing to the coupling between chlorine and hydrogen compounds.

In summary, comparing cases $\mathrm{a}$ and $\mathrm{b}$ one obtains from the simulations a $5-11 \%$ greater $\mathrm{Cl}$ mixing ratio. This leads to a larger $\mathrm{HCl}$ mixing ratio (up to $\sim 6 \%$ ) and an insignificant decrease of the $\mathrm{CH}_{4}$ mixing ratio at the end of the simulation period, whereas differences in the $\mathrm{ClO}$ mixing ratios are $<1 \%$. Furthermore, approximately $5 \%$ more ozone is destroyed when using case a during the Arctic polar winter.

\section{Conclusion}

The present results show that the photolysis of the $\mathrm{ClO}$ dimer does not lead to any detectable $\mathrm{ClO}$ formation. We estimate from the laboratory experiments, considering the signal-to-noise ratios at $250 \mathrm{~nm}$, that $\gamma_{\mathrm{Cl}} \geq 0.98$. The competing channel (6) is estimated to be of minor importance, $\gamma_{\mathrm{ClO}} \leq 0.02$, if it exists at all. At $308 \mathrm{~nm}$ no evicence for photolytic $\mathrm{ClO}$ formation is found, as well. The upper limit of $\gamma_{\mathrm{ClO}} \leq 0.10$ is a result of the smaller absorption cross section of $\mathrm{ClOOCl}$, which affects the decreased signal-to-noise ratio in photolysis mass spectra. This corresponds to $\gamma_{\mathrm{Cl}} \geq 0.90$ at $308 \mathrm{~nm}$. At both photolysis wavelengths ozone depletion proceeds efficiently via reactions $1-4$. This result confirms earlier work, where the quantum yield for $\mathrm{Cl}$ formation is reported to be unity. ${ }^{12}$

The present results corroborate the conclusions deduced from previous works and reduce the error limit of the primary quantum yield of $\mathrm{ClOOCl}$ photolysis. Model simulations yield significant differences for the ozone mixing ratio considering (a) $\mathrm{ClOOCl}$ decays exclusively via eq 2 , i.e., $\gamma_{\mathrm{Cl}}=1.0$, and (b) $\gamma_{\mathrm{Cl}}=0.9$ and $\gamma_{\mathrm{ClO}}=0.1$. Approximately $5 \%$ more ozone is destroyed in case a during the Arctic polar winter than in case b. This is a result of the higher efficiency of the $\mathrm{ClO}$ dimer cycle in case a. The efficiency of this cycle is highest under cold sunlit conditions, because at sufficiently high temperature, thermal decomposition of $\mathrm{ClOOCl}$ (cf. eq 1) competes with UVphotolysis. Therefore, in particular for Antarctic conditions it is crucial that only the photolysis channel (2) exists.

Acknowledgment. J. Plenge acknowledges financial support by the Deutsche Bundesstiftung Umwelt. Financial support by the Bundesministerium für Bildung und Forschung (BMBF), the European Union, and the Fonds der Chemischen Industrie is gratefully acknowledged.

\section{References and Notes} 207.

(1) Farman, J. C.; Gardiner, B. G.; Shanklin, J. D. Nature 1985, 315,
(2) Molina, L. T.; Molina, M. J. J. Phys. Chem. 1987, 91, 433.

(3) Eberstein, I. J. Geophys. Res. Lett. 1990, 17, 721.

(4) Minton, T. K.; Nelson, Ch. M.; Moore, T. A.; Okumura, M. Science 1992, 258, 1342 .

(5) McGrath, P. M.; Clemitshaw, K. C.; Rowland, F. S.; Hehre, W. J. J. Phys. Chem. 1990, 94, 6126.

(6) Lee, T. J.; McMichael Rohlfing, C.; Rice, J. E. J. Chem. Phys. 1992, 97, 6593

(7) Stanton, J. F.; Rittby, C. M. L.; Bartlett, R. J.; Toohey, D. W. J. Phys. Chem. 1991, 95, 2107. Stanton, J. F.; Bartlett, R. J. J. Chem. Phys. 1993, 98, 9335 .

(8) Zhu, R. S.; Lin, M. C. J. Chem. Phys. 2003, 118, 4094.

(9) Toniolo, A.; Granucci, G.; Inglese, S.; Persico, M. Phys. Chem. Chem. Phys. 2001, 3, 4266.

(10) Kaledin, A. L.; Morokuma, K. J. Chem. Phys. 2000, 113, 5750.

(11) Cox, R. A.; Hayman, G. D. Nature 1988, 332, 796.

(12) Molina, M. J.; Colussi, A. J.; Molina, L. T.; Schindler, R. N.; Tso, T.-L. Chem. Phys. Lett. 1990, 173, 310.

(13) Moore, T. A.; Okumura, M.; Seale, J. W.; Minton, T. K. J. Phys. Chem. 1999, 103, 1691.

(14) Schwell, M.; Jochims, H.-W.; Wassermann, B.; Rockland, U.; Flesch, R.; Rühl, E. J. Phys. Chem. 1996, 100, 10070.

(15) Flesch, R.; Schürmann, M. C.; Hunnekuhl, M.; Meiss, H.; Plenge, J.; Rühl, E. Rev. Sci. Instrum. 2000, 71, 1319.

(16) Flesch, R.; Rühl, E.; Hottmann, K.; Baumgärtel, H. J. Phys. Chem. 1993, 97, 837.

(17) Bemand, P. P.; Clyne, M. A. A.; Watson, R. T. J. Chem. Soc., Faraday Trans. 1 1973, 69, 1356.

(18) Burkholder, J. B.; Orlando, J. J.; Howard, C. J. J. Phys. Chem. 1990, 94, 687.

(19) Wayne, R. P.; Poulet, G.; Biggs, P.; Burrows, J. P.; Cox, R. A.; Crutzen, P. J.; Hayman, G. D.; Jenkin, M. E.; Le Bras, G.; Moortgart, G. K.; Platt, U.; Schindler, R. N. Atmos. Environ. 1995, 29, 2675.

(20) Huder, K. J.; deMore, W. B. J. Phys. Chem. 1995, 99, 3905.

(21) Flesch, R.; Plenge, J.; Schürmann, M.-C.; Kühl, S.; Klusmann, M.; Rühl, E. Surf. Rev. Lett. 2002, 9, 105.

(22) Flesch, R.; Plenge, J.; Kühl, S.; Klusmann, M.; Rühl, E. J. Chem. Phys. 2002, 117, 9663.

(23) Flesch, R.; Schürmann, M. C.; Hunnekuhl, M.; Meiss, H.; Plenge, J.; Rühl, E. Phys. Rev. A 2000, 62, 52723.

(24) Berkowitz, J. Photoabsorption, Photoionization, and Photoelectron Spectroscopy; Academic Press: New York, 1978.

(25) Plenge, J. Ph.D. Thesis, Universität Osnabrück, 2002

(26) Müller, H.S. P.; Willner, H. Ber. Bunsen-Ges. Phys. Chem. 1992 96,427

(27) Flesch, R.; Schürmann, M. C.; Plenge, J.; Hunnekuhl, M.; Meiss, H.; Bischof, M.; Rühl, E. Phys. Chem. Chem. Phys. 1999, 1, 5423.

(28) Maric, D.; Burrows, J. P.; Meller, R.; Moortgat, G. K. J. Photochem. Photobiol. A 1993, 70, 205.

(29) Anderson, J. G.; Toohey, D. W.; Brune, W. H. Science 1991, 251, 39.

(30) McKenna, D. S.; Konopka, P.; Grooss, J.-U.; Günther, G.; Müller, R.; Spang, R.; Offermann, D.; Orsolini, Y. J. Geophys. Res. 2002, 107, 4309.

(31) McKenna, D. S.; Grooss, J.-U.; Günther, G.; Konopka, P.; Müller, R.; Carver, G. J. Geophys. Res. 2002, 107, 4256.

(32) Vogel, B.; Stroh, F.; Grooss, J.-U.; Müller, R.; Deshler, T.; Karhu, J.; McKenna, D. S.; Müller, M.; Toohey, D.; Toon, G. C. J. Geophys. Res. 2003, 108, 8334 